\title{
A novel application of Transnasal Humidified Rapid Insufflation Ventilatory Exchange via the oral route in morbidly obese patient during monitored anesthesia care - A case report -
}

Received May 27, 2020

Revised July 4, 2020

Accepted July 23, 2020

\author{
Jaewoong Jung, Yang-Hoon Chung, and Won Seok Chae
}

Department of Anesthesiology and Pain Medicine, Soonchunhyang University Bucheon Hospital, Soonchunhyang University College of Medicine, Bucheon, Korea

Background: Transnasal Humidified Rapid Insufflation Ventilatory Exchange (THRIVE) is used to improve oxygenation, with the added benefit of a smaller increase in $\mathrm{CO}_{2}$ if self-respiration is maintained with THRIVE. Despite these advantages, the use of THRIVE through a nasal cannula is limited in situations such as epistaxis or a basal skull fracture.

Case: We successful used THRIVE, through the oral route under general anesthesia with spontaneous breathing in a morbidly obese patient (weight, $148 \mathrm{~kg}$; height, $183 \mathrm{~cm}$; body mass index, $44.2 \mathrm{~kg} / \mathrm{m}^{2}$ ) who received transnasal steroid injections due to subglottic stenosis.

Conclusions: THRIVE through the oral route may be an effective novel option, although further studies are needed.

Keywords: Airway management; Balanced anesthesia; Obesity, morbid; Otolaryngologic diseases.
Morbidly obese patients tend to desaturate faster than non-obese patients due to decreased functional residual capacity, increased $\mathrm{O}_{2}$ consumption, and increased shunt flow [1]. Airway management is more challenging in morbidly obese patients because of the likelihood of a difficult airway [2].

Transnasal Humidified Rapid Insufflation Ventilatory Exchange (THRIVE) has been widely used outside of the operating room, but its use in the operating room is now also increasing [3]. Optiflow ${ }^{\circledR}$ (Fisher \& Paykel Healthcare, New Zealand), a new commercial THRIVE device, supplies warmed, humidified, high flow $\mathrm{O}_{2}(\sim 70 \mathrm{~L} / \mathrm{min})$ through a nasal cannula. It can be applied over the entire range of anesthesia, from preoxygenation $[4,5]$ to post-extubation [6]. Optiflow ${ }^{\circledR}$ can also be safely applied in morbidly obese patients [7] to improve oxygenation and respiratory mechanics.

Despite the benefits of THRIVE, the use thereof through a nasal cannula is limited in situations such as nasal obstruction, epistaxis, and recent nasal trauma or surgery [8]. And in the case of steroid injection into the region of subglottic stenosis as adjunctive treatment after dilatation [9], the transoral approach with rigid laryngoscope is limited due to severe gag reflex.

Therefore, the transnasal approach is commonly performed with a laryngoscope with a flexible working channel. The transnasal approach may limit $\mathrm{O}_{2}$ supply through a nasal cannula. In such cases, $\mathrm{O}_{2}$ can be supplied through the oral route. We experienced a morbidly obese patient who received serial transnasal steroid injections due to

This is an Open Access article distributed under the terms of the Creative Commons Attribution Non-Commercial License (http://creativecommons.org/licenses/by-nc/4.0) which permits unrestricted non-commercial use, distribution, and reproduction in any medium, provided the original work is properly cited.

Copyright (c) the Korean Society of Anesthesiologists, 2020 
subglottic stenosis using a standard facial mask and THRIVE through the oral route under general anesthesia with spontaneous breathing. We report our experience and introduce the use of THRIVE through the oral route as an alternative for supplying $\mathrm{O}_{2}$.

\section{CASE REPORT}

This study was approved by the Institutional Review Board of Soonchunhyang University Bucheon Hospital (IRB No. 2020-02-026-001). And written informed consent, included the consent to publish images, was obtained from the patient in this study.

The patient was a 37 -year-old man $(148 \mathrm{~kg}, 183 \mathrm{~cm}$, body mass index [BMI] $44.2 \mathrm{~kg} / \mathrm{m}^{2}$ ) with a history of tracheostomy due to hypertensive intracranial hemorrhage that occurred 4 years ago. He was diagnosed with grade I tracheal stenosis above the tracheostomy site 2 years ago. Despite conservative treatment, dyspnea developed and the patient underwent endoscopic tracheal dilatation under general anesthesia. Baseline peripheral capillary $\mathrm{O}_{2}$ saturation $\left(\mathrm{SpO}_{2}\right)$ was $94 \%$ and Cormack-Lehane grade was 3 at the time of intubation. Surgery was performed using the intermittent apnea technique with extubation, and a total of six apnea events occurred, with a mean duration of apnea was 147 s. The lowest $\mathrm{SpO}_{2}$ was $64 \%$, and $\mathrm{SpO}_{2}$ recovered to 9698\% after manual ventilation via endotracheal tube. The patient had been treated conservatively after balloon dilatation with portable $\mathrm{O}_{2}$ at home. Dyspnea worsened again 1 year ago, despite $\mathrm{O}_{2}$ therapy, and serial fiberoptic steroid injections to the subglottic stenosis site were planned. In our hospital, fiberoptic steroid injections are usually performed according to the following steps. Topical anesthesia at nostrils is followed by sedation, applied by surgeon. The fiberscope is inserted through the nostril, and the glottis and lesion are sprayed with additional local anesthetics. Then, the lesion is injected with steroid. The otolaryngologist consulted us for safe sedation and monitoring due to the possibility of emergency caused by airway edema or airway obstruction. Considering the patient's general condition, symptoms, and experience of previous surgery, we decided to perform the operation under general anesthesia with spontaneous breathing in preparation for airway manipulation, because general anesthesia using the intermittent apnea technique could limit the view of surgical field and damage the larynx and subglottic lesions.

On entering the operating room, the patient was placed in a $30^{\circ}$ sitting position for the first steroid injection. Standard American Society of Anesthesiologists monitoring (non-invasive blood pressure [NIBP], electrocardiogram, and $\mathrm{SpO}_{2}$ ) and bispectral index (BIS) monitoring were applied. The baseline vital signs were as follows: BP, 105/52 $\mathrm{mmHg}$; heart rate (HR), 66 beats per minute (beats/min); $\mathrm{SpO}_{2}, 95 \%$. Oxygenation was applied at $6 \mathrm{~L} / \mathrm{min}_{2}$ through a standard facial mask. End-tidal $\mathrm{CO}_{2}\left(\mathrm{EtCO}_{2}\right)$ was monitored continuously by capnography to confirm self-respiration. Dexmedetomidine was used for sedation. After delivering a loading dose of $1 \mu \mathrm{g} / \mathrm{kg}$ over $10 \mathrm{~min}$, continuous infusion of $0.6 \mu \mathrm{g} / \mathrm{kg} / \mathrm{h}$ was maintained. During infusion of the loading dose, the $\mathrm{EtCO}_{2}$ level decreased gradually until apnea was induced. An oral airway was inserted and the jaw-thrust maneuver was applied to maintain airway patency and support self-respiration. After confirming that the patient was unresponsive to verbal commands and tactile stimulus, the surgery was started while self-respiration was maintained. The surgeon requested lowering of the facial mask so that it would not interfere with the procedure and applied topical anesthesia by packing gauze soaked with Bosmin ${ }^{\circledast}$ (0.1\% epinephrine) and Beracaine ${ }^{\circledR}(10 \%$ lidocaine) into both nostrils. The fiberscope was passed through the nostril to access the glottic and subglottic lesions, and additional $2 \%$ lidocaine was sprayed around glottis and lesions, and $3 \mathrm{ml}$ of tamcetone ${ }^{\circledR}$ (Triamcinolone $40 \mathrm{mg} / \mathrm{ml}$ ) was then injected. The procedure was interrupted by bag-valve-mask ventilation because $\mathrm{SpO}_{2}$ fell to $86 \%$. After ventilator assistance for $117 \mathrm{~s}, \mathrm{SpO}_{2}$ recovered to $96 \%$. During surgery, HR remained within $20 \%$ of the baseline, but BP increased by more than $20 \%$ of the baseline. However, systolic BP remained below $160 \mathrm{mmHg}$, so no additional drug administration was necessary. The value of BIS was maintained between 55 and 80 . The total surgery time was $20 \mathrm{~min}$ and the total anesthesia time was $40 \mathrm{~min}$. The patient was discharged after 1 day of monitoring in the Intensive Care Unit (ICU), without dyspnea or complications.

Dyspnea improved noticeably, but on physical examination, grade II subglottic stenosis and stridor remained, thus necessitating a second steroid injection 1 month later. Based on our previous experience, we considered that there was a need to improve oxygenation during the procedure, so we decided to apply Optiflow ${ }^{\circledR}$. In the same manner as in the first operation, the patient was placed in the $30^{\circ}$ sitting position, and standard American Society of Anesthesiologists and BIS monitoring were applied. Baseline vital signs were as follows: $\mathrm{BP}, 102 / 58 \mathrm{mmHg}$; $\mathrm{HR}, 70$ beats/ 
min; and $\mathrm{SpO}_{2}, 94 \% . \mathrm{O}_{2}$ (100\% warmed, humidified) was supplied through a nasal cannula at a rate of $30 \mathrm{~L} / \mathrm{min}$ for preoxygenation. The patient tolerated this well, without any complaints. Dexmedetomidine was used for sedation at the same dose as before. Once the patient was unconscious, the $\mathrm{O}_{2}$ flow rate was raised to $70 \mathrm{~L} / \mathrm{min}$. $\mathrm{EtCO}_{2}$ was monitored by placing the $\mathrm{EtCO}_{2}$ sampling line at the nostril next to the Optiflow ${ }^{\circledR}$ nasal cannula; however, a low value was obtained, so we could only confirm self-respiration by monitoring the shape of the waveform (Fig. 1A). Topical anesthesia was applied by packing gauze into both nostrils. This disturbed the $\mathrm{O}_{2}$ supply through the Optiflow ${ }^{\circledR}$ nasal cannula; therefore, we inserted an oral airway to maintain airway patency, and the Optiflow ${ }^{\circledR}$ nasal cannula was transferred to the opening of the oral airway. The $\mathrm{EtCO}_{2}$ line was also transferred to the opening of the oral airway, but it still showed a low value; thus, only the shape of waveform was monitored (Fig. 1B). $\mathrm{SpO}_{2}$ was maintained at 98 $100 \%$, and no intervention, such as mask ventilation or jet ventilation, was required during surgery. Despite self-respiration, there was a drop in $\mathrm{SpO}_{2}$ to $86 \%$ (Fig. 1C) due to $\mathrm{O}_{2}$ leakage; the Optiflow ${ }^{\circledR}$ nasal cannula dislocated from the airway opening. After fixing the nasal cannula to the airway with plaster (Fig. 2), $\mathrm{SpO}_{2}$ immediately recovered to 99\% and no additional desaturation events occurred. The vital signs were stable within $20 \%$ of baseline. Additional bolus of midazolam was injected to prevent the event of awareness because the value of BIS was maintained between 70 and 79 when the procedure was performed; $1 \mathrm{mg}$ for oral airway insertion, $2 \mathrm{mg}$ for gauze packing into both nostrils. During the operation, the value of BIS was well maintained between 35 and 50, and spontaneous breathing was generally maintained well. The patient endured

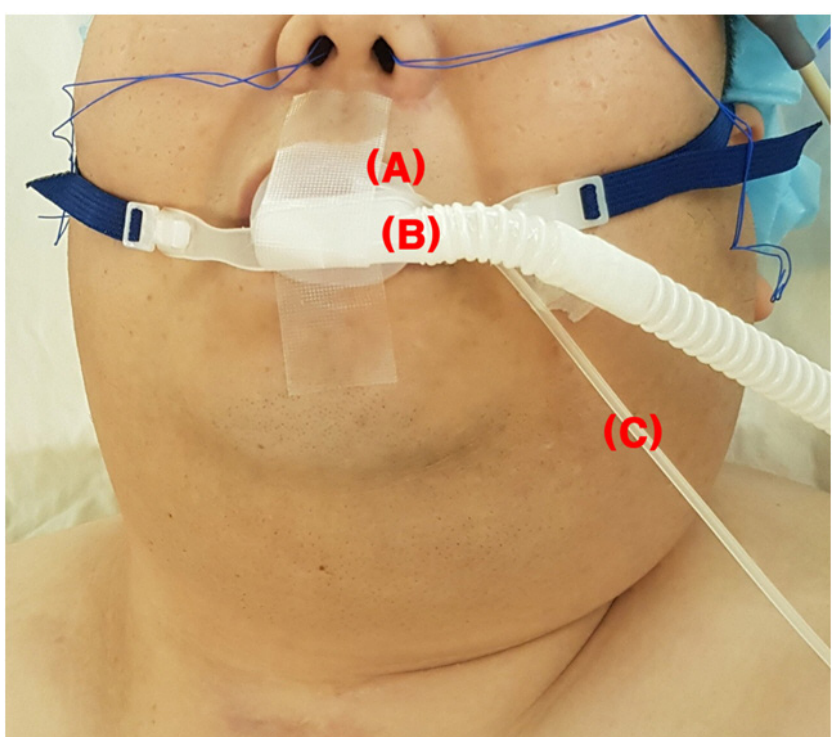

Fig. 2. (A) Oral airway, (B) Optiflow nasal cannula, (C) $\mathrm{EtCO}_{2}$ sample line. $\mathrm{EtCO}_{2}$ : end-tidal $\mathrm{CO}_{2}$.

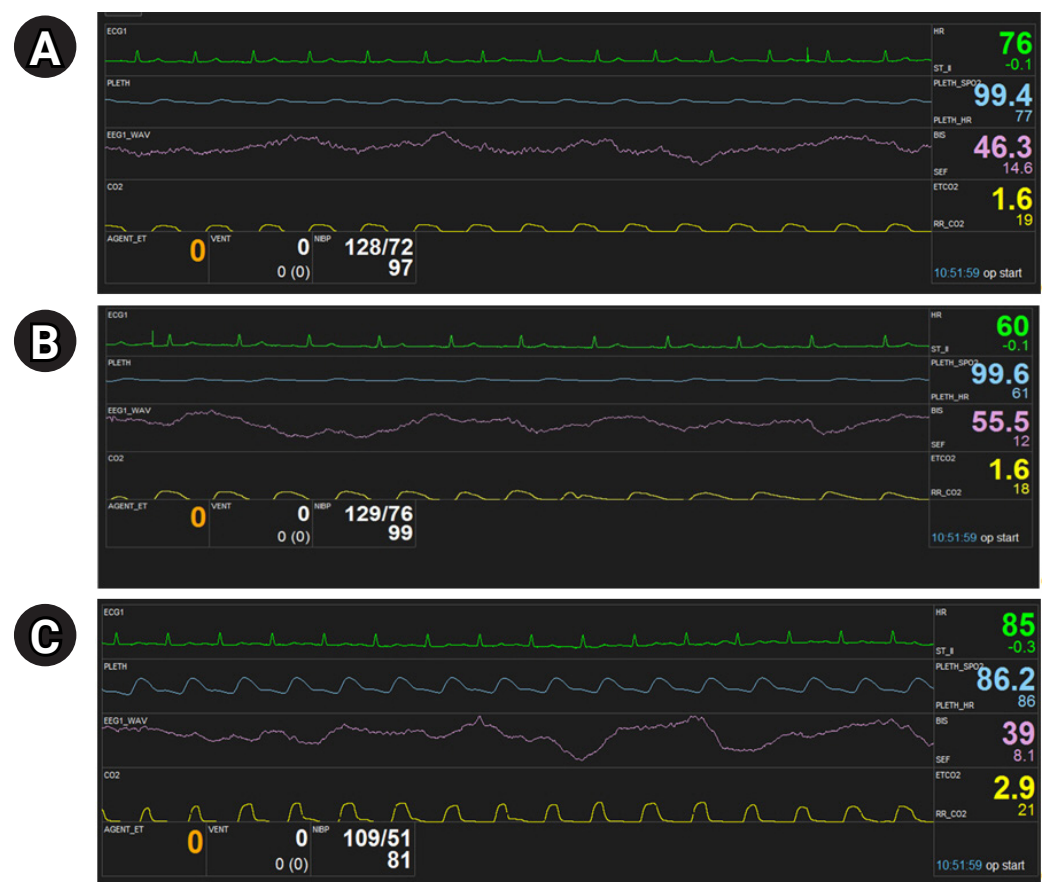

Fig. 1. (A) End-tidal $\mathrm{CO}_{2}\left(\mathrm{EtCO}_{2}\right)$ at nostril. (B) $\mathrm{EtCO}_{2}$ at oral airway. (C) Desaturation event. 
the surgical stimuli without coughing and movement throughout entire operation. The total operation time was $15 \mathrm{~min}$ and total anesthesia time was $40 \mathrm{~min}$. The surgeon had prepared jet ventilation because of the experience during the previous surgery, but ultimately did not use it; thus, the surgeon was highly satisfied with THRIVE. After the surgery, the patient was transferred to the ICU. Arterial Blood Gas Analysis (aBGA) was performed after arrival in the ICU; partial pressure of $\mathrm{O}_{2}, 94 \mathrm{mmHg}$; partial pressure of $\mathrm{CO}_{2}\left(\mathrm{PaCO}_{2}\right), 49 \mathrm{mmHg} ; \mathrm{pH}, 7.30$; bicarbonate, 21.3 $\mathrm{mEq} / \mathrm{L}$. The patient was discharged after 1 day of monitoring without complications.

\section{DISCUSSION}

We confirmed the effectiveness of THRIVE through the oral route in a morbidly obese patient receiving steroid injections due to subglottic stenosis. Some patients may be contraindicated for THRIVE through the nasal route, and a nasal cannula can prevent manipulation of the fiberscope during trannasal approach. In our case, it was impossible to supply $\mathrm{O}_{2}$ through a nasal route due to nasal packing, so we used the oral approach using an oral airway. Heard et al. [10] reported that oxygenation through a Ring-Adair-Elwyn (RAE) tube placed in buccal region results in significantly less desaturation in patients with a BMI of 30-40 kg/ $\mathrm{m}^{2}$. Achar et al. [11] reported that oxygenation through a nasopharyngeal catheter is better than through nasal prongs. These results were based on the distance from the $\mathrm{O}_{2}$ supply outlet to the laryngeal inlet being reduced, such that $\mathrm{O}_{2}$ was effectively delivered to the inlet [11]. In our case, high $\mathrm{O}_{2}$ flow might be delivered well by reducing the distance to the laryngeal inlet through the oral airway as mentioned above. Also there was a desaturation event occurred due to dislocation of the THRIVE nasal cannula from the airway opening. Toner et al. [12] reported desaturation due to obstruction of an RAE tube. Therefore, it is important to note that patency of airway and the $\mathrm{O}_{2}$ supply device must be maintained.

$\mathrm{EtCO}_{2}$ monitoring is necessary to confirm self-respiration and $\mathrm{CO}_{2}$ accumulation. However, because $\mathrm{EtCO}_{2}$ monitoring is limited when using THRIVE, alternative option for $\mathrm{CO}_{2}$ monitoring is essential. The rate of increase in $\mathrm{EtCO}_{2}$ is lower in the case of THRIVE with spontaneous breathing [13] than THRIVE with apneic oxygenation [14]. In our case, postoperative aBGA showed that $\mathrm{PaCO}_{2}$ was 49 $\mathrm{mmHg}$, which was not a significantly increase. Several studies have reported a difference between $\mathrm{EtCO}_{2}$ and $\mathrm{PaCO}_{2}$ over time when using THRIVE, but a good correlation between $\mathrm{PaCO}_{2}$ and transcutaneous $\mathrm{CO}_{2}\left(\mathrm{tcCO}_{2}\right)$ has also been reported $[14,15]$. Therefore, it is reasonable to consider $\mathrm{tcCO}_{2}$ monitoring when using THRIVE. The lack of $\mathrm{CO}_{2}$ monitoring through $\mathrm{tcCO}_{2}$ may be limitation in our case.

Our first attempt using a facial mask led to frequent desaturation events. However, our second attempt, using the THRIVE through the oral route, resulted in stable $\mathrm{O}_{2}$ saturation. The effectiveness of our technique cannot be confirmed based on only one case. Thus, further investigations are needed to determine whether supplying $\mathrm{O}_{2}$ through the oral route using THRIVE is comparable to supplying $\mathrm{O}_{2}$ through a nasal cannula. However, our experience demonstrates the possibility of applying THRIVE through the oral route.

In conclusion, THRIVE may be beneficial in morbidly obese patients undergoing upper airway surgery under general anesthesia with spontaneous breathing. As in our case, in cases where applying THRIVE through a nasal cannula is difficult, effective oxygenation can be achieved by application through the oral route.

\section{CONFLICTS OF INTEREST}

No potential conflict of interest relevant to this article was reported.

\section{AUTHOR CONTRIBUTIONS}

Conceptualization: Jaewoong Jung, Won Seok Chae. Data curation: Jaewoong Jung. Methodology: Yang-Hoon Chung. Writing - original draft: Jaewoong Jung. Writing - review \& editing: Yang-Hoon Chung. Investigation: Jaewoong Jung. Supervision: Won Seok Chae.

\section{ORCID}

Jaewoong Jung, https://orcid.org/0000-0003-0624-1713 Yang-Hoon Chung, https://orcid.org/0000-0002-9823-9030 Won Seok Chae, https://orcid.org/0000-0002-5772-1525

\section{REFERENCES}

1. Bouroche G, Bourgain JL. Preoxygenation and general anesthesia: a review. Minerva Anestesiol 2015; 81: 910-20. 
2. Huang L, Dharmawardana N, Badenoch A, Ooi EH. A review of the use of transnasal humidified rapid insufflation ventilatory exchange for patients undergoing surgery in the shared airway setting. J Anesth 2020; 34: 134-43.

3. Yang SH, Wu CY, Tseng WH, Cherng WY, Hsiao TY, Cheng YJ, et al. Nonintubated laryngomicrosurgery with transnasal humidified rapid-insufflation ventilatory exchange: a case series. J Formos Med Assoc 2019; 118: 1138-43.

4. To K, Harding F, Scott M, Milligan P, Nixon IJ, Adamson R, et al. The use of transnasal humidified rapid-insufflation ventilatory exchange in 17 cases of subglottic stenosis. Clin Otolaryngol 2017; 42: 1407-10.

5. Maupeu L, Raguin T, Hengen M, Diemunsch P, Schultz P. Indications of transnasal humidified rapid-insufflation ventilatory exchange (THRIVE) in laryngoscopy, a prospective study of 19 cases. Clin Otolaryngol 2019; 44: 182-6.

6. Rittayamai N, Tscheikuna J, Rujiwit P. High-flow nasal cannula versus conventional oxygen therapy after endotracheal extubation: a randomized crossover physiologic study. Respir Care 2014; 59: 485-90.

7. Lee SJ, Quek KH. Facilitating airway surgery in a morbidly obese patient using transnasal humidified rapid insufflation ventilatory exchange (THRIVE). Case Rep Anesthesiol 2018; 2018: 5310342.

8. Renda T, Corrado A, Iskandar G, Pelaia G, Abdalla K, Navalesi P. High-flow nasal oxygen therapy in intensive care and anaesthesia. Br J Anaesth 2018; 120: 18-27.

9. Bertelsen C, Shoffel-Havakuk H, O'Dell K, Johns MM 3rd, Reder LS. Serial in-office intralesional steroid injections in airway stenosis. JAMA Otolaryngol Head Neck Surg 2018; 144: 203-10.

10. Heard A, Toner AJ, Evans JR, Aranda Palacios AM, Lauer S. Apneic oxygenation during prolonged laryngoscopy in obese patients: a randomized, controlled trial of buccal RAE tube oxygen administration. Anesth Analg 2017; 124: 1162-7.

11. Achar SK, Pai AJ, Shenoy UK. Apneic oxygenation during simulated prolonged difficult laryngoscopy: comparison of nasal prongs versus nasopharyngeal catheter: a prospective randomized controlled study. Anesth Essays Res 2014; 8: 63-7.

12. Toner AJ, Douglas SG, Bailey MA, Avis HJ, Pillai AV, Phillips M, et al. Effect of apneic oxygenation on tracheal oxygen levels, tracheal pressure, and carbon dioxide accumulation: a randomized, controlled trial of buccal oxygen administration. Anesth Analg 2019; 128: 1154-9.

13. Booth AWG, Vidhani K, Lee PK, Thomsett CM. Spontaneous respiration using intravenous anaesthesia and Hi-flow nasal oxygen (STRIVE Hi) maintains oxygenation and airway patency during management of the obstructed airway: an observational study. Br J Anaesth 2017; 118: 444-51.

14. Gustafsson IM, Lodenius Å, Tunelli J, Ullman J, Jonsson Fagerlund M. Apnoeic oxygenation in adults under general anaesthesia using transnasal humidified rapid-insufflation ventilatory exchange (THRIVE) - a physiological study. Br J Anaesth 2017; 118: 610-7.

15. Hermez LA, Spence CJ, Payton MJ, Nouraei SAR, Patel A, Barnes TH. A physiological study to determine the mechanism of carbon dioxide clearance during apnoea when using transnasal humidified rapid insufflation ventilatory exchange (THRIVE). Anaesthesia 2019; 74: 441-9. 